\title{
APPENDIX II. INTERSTITIAL WATER STUDIES ON SMALL CORE SAMPLES, LEGS 16, 17, AND $18^{1}$
}

\author{
Lee S. Waterman and Frederick L. Sayles, Woods Hole Oceanographic Institution, Woods Hole, Massachusetts, \\ and \\ Frank T. Manheim, United States Geological Survey, Woods Hole, Massachusetts
}

\begin{abstract}
Legs 16,17 , and 18 encountered three groups of sediment types: rapidly deposited biogenic deposits, showing marked changes in interstitial calcium, magnesium, and strontium; slowly deposited biogenic deposits, showing little variability in pore fluids other than elevated silica concentrations; and terrigenous deposits. The latter showed the usual loss of sulfate and combination of diagenetic reactions culminating in loss of $\mathrm{Na}^{+}$, $\mathrm{K}^{+}, \mathrm{Mg}^{++}$, with variable changes in $\mathrm{Ca}^{++}$. Very high barium concentrations (to $59 \mathrm{mg} / \mathrm{kg}$ ) occurred at Site 178 (Leg 18).
\end{abstract}

\section{INTRODUCTION}

A total of 315 sediment samples from Legs 16, 17, and 18 were squeezed for interstitial water. Of these, 107 were selected for a comprehensive analysis of the major inorganic constituents (Tables 1 and 2). This represents a departure from the practice, employed for Legs 1 through 14, of analyzing every pore water sample collected. Emphasis has been placed on the continental margin sites with more than 60 percent of the samples selected for analysis coming from Leg 18. Analytical methods were identical to those outlined in earlier volumes of this series. We wish to thank Wen Chang, James O'Neill, and Irene Uhlitzsch for performing the analyses and data reduction.

\section{RESULTS}

Sites drilled on Legs 16,17 , and 18 can be grouped into three categories, each exhibiting a characteristic pore water behavior. These are (1) rapidly deposited, open-ocean biogenic sediments; (2) slowly deposited unreactive biogenic sediments, and (3) continental margin sediments principally of terrigenous origins. All three types have been described and discussed in previous reports in this series.

Site 157 (Leg 16) is a typical example of the first type. An enrichment of $\mathrm{Ca}^{++}$relative to surface ocean water is accompanied by depletion of $\mathrm{Mg}^{++}$and reduction of $\mathrm{SO}_{\overline{4}}$. Sites $158,164,165,167,170,173$, and 177 also belong in this category. Calcium enrichments range from 1.3 to 3.2 times the open-ocean surface water concentrations, whereas

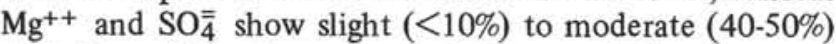
depletions. Strontium concentrations, relative to ocean water, are enriched to some extent at all of these locations. Sites 164, 165, 170, and 173 exhibit enrichments of 10 to 70 percent; whereas Sites 157,158 , and 167 show 4 - to 8 -fold increases. Two of the three sites in the high $\mathrm{Sr}^{++}$

\footnotetext{
${ }^{1}$ Contribution No. 3076 of the Woods Hole Oceanographic Institution.
}

category (157 and 158) correlate with the largest $\mathrm{Ca}^{++}$ enrichments and $\mathrm{Mg}^{++}$depletions. This correspondence has been noted previously and interpreted as reflecting carbonate recrystallization (Manheim and Sayles, 1971).

Most of the sites drilled on Leg 16 (159 through 163) along with Sites 166 and 171 from Leg 17 belong to the second category listed above. A minimum of samples (usually top, middle, and near the bottom of the hole) were analyzed to establish that the major constituents of pore fluids exhibit insignificant or marginally significant changes with depth and location. These cores are typical of previously analyzed samples from other pelagic areas of the Pacific (see Initial Reports of the Deep Sea Drilling Project, Volumes V through IX). Only at Site 163 is there slight evidence of reactivity.

Eight of 23 sites reported here belong to the continental margin category. Terrigenous muds and silts predominate at all of these sites. Analyses are concentrated at four sites $(155,174,178$, and 180) where many samples, reasonably distributed with depth were available. Continental margin sediments typically show severe and sometimes total reduction of $\mathrm{SO}_{4}^{\overline{4}}$; a depletion of $\mathrm{Ca}^{++}$in the upper part of the deposits giving way to enrichment at depth; and depletion of both $\mathrm{K}^{+}$and $\mathrm{Mg}^{++}$. The top 440 meters were not cored at Site 155 . Pore fluids were obtained from the first nine cores which cover an 87 meter interval. Sites 174 and 178 were cored and sampled to depths greater than 700 meters; Site 180 , to 456 meters. Sulfate, depleted by about 10 percent in the topmost samples from Sites 174,178 , and 180 , drops sharply in the first 90 meters. Below this level depletion is nearly complete, within analytical uncertainty in most samples. Calcium depletion in the uppermost samples is followed at depth by gradual enrichment at two sites (174 and 180). $\mathrm{Mg}^{++}$and $\mathrm{K}^{+}$are depleted at all four sites.

Site 177 is unusual inasmuch as the pore fluids behave chemically like the type 1 biogenic group while the sediments contain a significant proportion of terrigenous material. The rather mild concentration changes probably reflect a relatively slow deposition rate (for terrigenous 
sediments). Site 178 is also somewhat unusual in that strong depletion of $\mathrm{SO}_{\overline{4}}$ in the upper portion of the hole is not accompanied by $\mathrm{Ca}^{++}$loss as is the case at Sites 174 and 180. Rather, enrichment is seen at 82 meters. The concurrent loss of $\mathrm{Mg}^{++}$is large and quite typical of terrigenous sediment deposits.

The unusually low $\mathrm{Na}^{+}$and $\mathrm{Cl}^{-}$values of Sample 155-6-4, while suspect, do not appear to result from either storage of the pore fluid or manipulation during analysis. Shipboard and shore laboratory salinities agree within the limits of uncertainty of the refractometer readings $( \pm 0.2 \%)$. Unexplained sudden variations of this type have in the past tended to be artifacts of some type. In this case it seems possible that the squeezed fluid or natural sediment has somehow been freshened artifically.

Cation values, particularly $\mathrm{K}^{+}$, for Sample 180-11(CC) show abrupt departure from more or less smooth trends with depth. These deviations may be artifacts of sample collection and processing (of unknown type) since this was a core catcher sample and only $1 \mathrm{ml}$ of water was extracted after nearly 1 hour of squeezing.

Among the trace constituents, barium displays particularly large concentrations in interstital waters from Site 178. Toward the base of the section, in hard olive gray muds 690 meters below the sea floor, values as high as 59 ppm occur. As seen in Figure 1, barium and sulfate concentrations in the interstitial waters of Site 178 generally vary in opposite directions, as one might expect from the limiting effect of $\mathrm{BaSO}_{4}$ solubility. However, at depth the molecular product of $[\mathrm{Ba}]\left[\mathrm{SO}_{4}\right]$ far exceeds the value given by $\mathrm{Li}$ et al. (in press) for the apparent solubility product of $\mathrm{BaSO}_{4}\left(\left[\mathrm{Ba}^{++}\right]\left[\mathrm{SO}_{4}^{\overline{\bar{n}}}\right]=1.1 \times 10^{-8} \mathrm{gmole} / 1\right.$ at $1^{\circ} \mathrm{C}$ and 500 bars). This phenomenon was first noted from studying DSDP interstitial water data. It was attributed to the existence of organic complexes of barium; especially good sources of $\mathrm{Ba}^{++}$are diatoms of the Chaetoceros and Rhizosolenia types.

Silica concentrations show good correlation with lithology. The highest values, approaching $40 \mathrm{mg} / \mathrm{kg} \mathrm{Si}$ or even higher, occur in biogenic oozes of Site 157, on the Carnegie Ridge off Equador; at the base of Site 158, Cocos Ridge; and in a nearly pure diatomite at the base of Site 173, on the continental slope off Cape Mendocino (California). Notwithstanding the presence of amorphous silica of diatom origin, clayey sediments in the northeast Pacific generally showed considerably lower silica concentrations. In such sediments the apparent solubility of amorphous silica may be reduced by surface absorption of metal ions (e.g., $\mathrm{Mg}^{++}, \mathrm{K}^{+} \mathrm{Na}^{+}$) to form authigenic silicates (Hurd, 1972).

\section{REFERENCES}

Hurd, D. C., 1972. Interactions of Biogenic Opal, Sediment and Seawater in the Central Equatorial Pacific. Hawaii Inst. Geophys. Univ. Hawaii. 72-22.81.

Li, Y. H., Ku, T. L., Mathieu, G. and Wolgemuth, K., in press. Barium in the Indian Antarctic Ocean south of Australia. Earth Planet. Sci. Letters.

Manheim, F. T. and Sayles, F. L., 1971. Interstitial water studies on small core samples, Leg 8. In Tracey, J. I. Jr., et al, Sutton, G. H., 1971. Initial Reports of the Deep Sea Drilling Project, Volume VIII. Washington (U. S. Government Printing Office). 856. 
TABLE 1

Major Constituents of Pore Fluids, Legs 16, 17, and 18. Values in $\mathrm{g} / \mathrm{kg}(\%)$ Except as Noted

\begin{tabular}{|c|c|c|c|c|c|c|c|c|c|c|c|c|c|c|c|c|c|c|}
\hline $\begin{array}{c}\text { Sample } \\
\text { Designation }\end{array}$ & $\begin{array}{l}\text { Depth } \\
\text { (m) }\end{array}$ & Age & Description & $\mathrm{Na}^{\mathrm{a}}$ & $\mathrm{Nab}$ & K & $\mathrm{Ca}$ & $\mathrm{Mg}$ & $\begin{array}{c}\text { Total } \\
\text { Cations } \\
\text { (meq/ } \\
\mathrm{kg} \text { ) }\end{array}$ & $\mathrm{Cl}$ & $\mathrm{SO}_{4}$ & $\begin{array}{l}\text { Alk. } \\
(\mathrm{meq} / \\
\mathrm{kg})\end{array}$ & $\mathrm{HCO}_{3}^{\mathrm{c}}$ & $\begin{array}{c}\text { Total } \\
\text { Anions } \\
\text { (meq/ } \\
\mathrm{kg})\end{array}$ & Sum ${ }^{d}$ & Salinitye & $\begin{array}{l}\mathrm{H}_{2} \mathrm{O}^{\mathrm{f}} \\
(\% \circ)\end{array}$ & $\mathrm{pH}^{\mathrm{f}}$ \\
\hline \multicolumn{19}{|l|}{ LEG 16} \\
\hline \multicolumn{19}{|c|}{ Hole $155\left(06^{\circ} 07.4^{\prime} \mathrm{N}, 81^{\circ} 02.6^{\prime} \mathrm{W}\right.$, water depth $2752 \mathrm{~m}$, Panama Basin) } \\
\hline Surface ocean & in water & & & 9.1 & 8.9 & 0.32 & 0.35 & 1.07 & 500 & 16.3 & 2.27 & 2.6 & 0.16 & 509 & 29.6 & 29.7 & - & - \\
\hline $155-1-6$ & 442 & Upper Miocene & Olive and light olive gray marl, mottled. & 9.9 & 10.0 & 0.17 & 1.07 & 0.23 & 513 & 18.0 & $<0.01$ & 0.5 & 0.03 & 507 & 29.4 & 29.7 & - & 8.2 \\
\hline $2-6$ & 451 & Upper Miocene & Medium greenish gray mudstone. & 10.0 & 9.8 & 0.15 & 1.16 & 0.25 & 507 & 18.1 & 0.04 & 0.4 & 0.03 & 519 & 29.7 & 29.7 & - & 7.3 \\
\hline $3-6$ & 460 & Upper Miocene & Varicolored olive gray marly clay. & 10.5 & 10.5 & 0.14 & 1.23 & 0.22 & 539 & 19.0 & 0.05 & 1.4 & 0.08 & 538 & 31.2 & 31.4 & - & 8.5 \\
\hline 4-6 & 469 & Upper Miocene & Olive gray claystone, massive, waxy. & 10.4 & 10.5 & 0.14 & 1.26 & 0.22 & 540 & 18.9 & 0.10 & 0.7 & 0.04 & 536 & 31.1 & 30.5 & - & 8.4 \\
\hline $5-6$ & 478 & Upper Miocene & Olive gray claystone & 10.1 & 10.1 & 0.13 & 1.34 & 0.21 & 529 & 18.6 & 0.04 & 0.7 & 0.04 & 528 & 30.5 & 30.8 & - & 8.4 \\
\hline $6-4$ & 484 & Middle Miocene & $\begin{array}{l}\text { Greenish gray and dusky yellow green } \\
\text { marl with olive gray pyritic mottles. }\end{array}$ & 9.3 & 9.4 & 0.10 & 1.38 & 0.29 & 503 & 17.4 & 0.27 & 1.3 & 0.08 & 499 & 28.8 & 29.4 & - & 7.7 \\
\hline $7-2$ & 490 & Middle Miocene & $\begin{array}{l}\text { Light olive gray dolomitic chalk, } \\
\text { well indurated. }\end{array}$ & 10.5 & 10.5 & 0.15 & 1.24 & 0.20 & 540 & 19.0 & 0.18 & 0.6 & 0.04 & 540 & 31.3 & 31.4 & - & 8.5 \\
\hline $8(\mathrm{CC})$ & 506 & Middle Miocene & Yellowish to light olive gray chalk-marl. & 10.1 & 10.2 & 0.16 & 1.36 & 0.32 & 540 & 18.5 & 0.67 & 0.4 & 0.02 & 536 & 31.1 & 30.8 & - & 7.5 \\
\hline $9(\mathrm{CC})$ & 515 & Middle Miocene & Light gray chalk ooze. & 10.6 & 10.7 & 0.16 & 1.38 & 0.28 & 559 & 19.3 & 0.58 & 0.1 & 0.01 & 560 & 32.3 & 33.0 & - & 7.4 \\
\hline \multicolumn{19}{|c|}{ Hole $157\left(01^{\circ} 45.7^{\prime} \mathrm{W}\right.$, water depth $2591 \mathrm{~m}$, Carnegie Ridge) } \\
\hline $157-16-6$ & 144 & Upper Pliocene & $\begin{array}{l}\text { Pale olive nanno chalk ooze, mottled, } \\
\mathrm{H}_{2} \mathrm{~S} \text { odor. }\end{array}$ & 10.9 & 10.7 & 0.38 & 0.40 & 1.22 & 593 & 19.6 & 2.24 & 4.6 & 0.28 & 604 & 35.0 & 35.2 & - & 7.2 \\
\hline $36-3$ & 327 & Upper Miocene & $\begin{array}{l}\text { Light greenish gray to yellowish gray } \\
\text { nanno chalk, mottles. }\end{array}$ & 10.7 & 10.5 & 0.32 & 0.74 & 0.97 & 579 & 19.3 & 2.10 & 3.3 & 0.20 & 591 & 34.3 & 34.7 & - & 7.1 \\
\hline $39-1$ & 346 & Upper Miocene & $\begin{array}{l}\text { Yellowish gray to pale olive nanno } \\
\text { chalk, mottled and burrowed. }\end{array}$ & 10.8 & 10.5 & 0.27 & 1.07 & 0.76 & 578 & 19.3 & 2.24 & 0.9 & 0.06 & 592 & 34.5 & 34.4 & - & 7.1 \\
\hline \multicolumn{19}{|c|}{ Hole $158\left(0.6^{\circ} 37.4^{\prime} \mathrm{N}, 85^{\circ} 14.2^{\prime} \mathrm{W}\right.$, water depth $1953 \mathrm{~m}$, Cocos Ridge) } \\
\hline $158-2-5$ & 15 & Pleistocene & $\begin{array}{l}\text { Grayish to dusky yellow green foram- } \\
\text { nanno chalk ooze. }\end{array}$ & 10.8 & 10.7 & 0.44 & 0.46 & 1.17 & 594 & 19.4 & 2.49 & 3.0 & 0.18 & 601 & 34.9 & 35.2 & 52 & 7.4 \\
\hline $13-5$ & 114 & Upper Miocene & $\begin{array}{l}\text { Medium greenish gray nanno chalk } \\
\text { ooze, forams and rads abundant, light } \\
\text { olive gray mottling. }\end{array}$ & 10.7 & 10.5 & 0.38 & 0.91 & 0.90 & 584 & 19.6 & 1.89 & 1.2 & 0.08 & 592 & 34.5 & 34.7 & - & 7.2 \\
\hline $33-2$ & 293 & Middle Miocene & $\begin{array}{l}\text { Grayish to dusky yellow green nanno } \\
\text { chalk with forams, nannos, rads, and } \\
\text { silicoflagellates. }\end{array}$ & 10.2 & 10.0 & 0.29 & 1.33 & 0.80 & 576 & 19.2 & 1.99 & 0.4 & 0.03 & 583 & 33.8 & 34.4 & 38 & 7.1 \\
\hline \multicolumn{19}{|c|}{ Hole $159\left(12^{\circ} 19.9^{\prime} \mathrm{N}, 122^{\circ} 17.3^{\prime} \mathrm{W}\right.$, water depth $4484 \mathrm{~m}$, midway between Clipperton and Clarion fracture zones) } \\
\hline $\begin{array}{l}159-2-6 \\
12-5\end{array}$ & $\begin{array}{r}16 \\
105\end{array}$ & $\begin{array}{l}\text { Upper Miocene } \\
\text { Lower Miocene }\end{array}$ & Dark to dusky yellowish brown clay. & 10.8 & 10.6 & 0.48 & 0.40 & 1.23 & $\begin{array}{l}595 \\
589\end{array}$ & 19.3 & 2.69 & 3.0 & 0.18 & 604 & 35.1 & 35.2 & 65 & 7.4 \\
\hline $160-2-4$ & 14 & ? & $\begin{array}{l}\text { Medium brown and grayish orange } \\
\text { zeolitic clay. }\end{array}$ & 10.6 & 10.5 & 0.46 & 0.40 & 1.24 & 589 & 19.2 & 2.52 & 2.8 & 0.17 & 596 & 34.6 & 34.6 & - & 7.4 \\
\hline $6-5$ & 51 & Upper Oligocene & $\begin{array}{l}\text { Pale yellowish orange nanno chalk } \\
\text { ooze. }\end{array}$ & 10.9 & 10.6 & 0.43 & 0.40 & 1.28 & 597 & 19.5 & 2.65 & 2.4 & 0.14 & 607 & 35.3 & 35.2 & 45 & 7.4 \\
\hline
\end{tabular}




\begin{tabular}{|c|c|c|c|c|c|c|c|c|c|c|c|c|c|c|c|c|c|c|}
\hline $\begin{array}{c}\text { Sample } \\
\text { Designation }\end{array}$ & $\begin{array}{l}\text { Depth } \\
\text { (m) }\end{array}$ & Age & Description & $\mathrm{Na}^{\mathrm{a}}$ & $\mathrm{Na}^{\mathrm{b}}$ & $\mathrm{K}$ & $\mathrm{Ca}$ & $\mathrm{Mg}$ & $\begin{array}{l}\text { Total } \\
\text { Cations } \\
\text { (meq/ } \\
\mathrm{kg} \text { ) }\end{array}$ & $\mathrm{Cl}$ & $\mathrm{SO}_{4}$ & $\begin{array}{l}\text { Alk. } \\
(\mathrm{meq} / \\
\mathrm{kg})\end{array}$ & $\mathrm{HCO}_{3}^{\mathrm{c}}$ & $\begin{array}{l}\text { Total } \\
\text { Anions } \\
\text { (meq/ } \\
\mathrm{kg})\end{array}$ & Sum ${ }^{\mathrm{d}}$ & Salinity $^{\mathrm{e}}$ & $\begin{array}{l}\mathrm{H}_{2} \mathrm{O}^{\mathrm{f}} \\
(\% \circ)\end{array}$ & $\mathrm{pH}^{\mathrm{f}}$ \\
\hline \multicolumn{19}{|c|}{ Holes 161 and $161 \mathrm{~A}\left(10^{\circ} 40.3^{\prime} \mathrm{N}, 139^{\circ} 57.2^{\prime} \mathrm{W}\right.$, water depth $4939 \mathrm{~m}$, midway between Clipperton and Clarion fracture zones) } \\
\hline $161-9-4$ & 76 & Upper Oligocene & $\begin{array}{l}\text { White nanno chalk ooze, very thin } \\
\text { beds of yellowish gray nanno chalk } \\
\text { ooze. }\end{array}$ & 10.8 & 10.6 & 0.43 & 0.40 & 1.25 & 594 & 19.5 & 2.41 & 1.6 & 0.10 & 601 & 34.9 & 35.2 & 35 & 7.5 \\
\hline $161 \mathrm{~A}-11-4$ & 214 & Upper Eocene & $\begin{array}{l}\text { Dark yellowish brown clay and } \\
\text { ferruginous aggregates (intense bur- } \\
\text { rowing and mottling. }\end{array}$ & 10.8 & 10.6 & 0.44 & 0.41 & 1.21 & 592 & 19.4 & 2.55 & 2.8 & 0.17 & 603 & 35.0 & 34.9 & 50 & 7.5 \\
\hline \multicolumn{19}{|c|}{ Hole $162\left(14^{\circ} 52.2^{\prime} \mathrm{N}, 140^{\circ} 02.6^{\prime} \mathrm{W}\right.$, water depth $4854 \mathrm{~m}, 80 \mathrm{~km}$ south of Clarion Fracture Zone) } \\
\hline Surface ocean & in water & & & 10.6 & 10.4 & 0.38 & 0.40 & 1.26 & 587 & 19.0 & 2.60 & 2.1 & 0.13 & 591 & 34.4 & 34.4 & - & - \\
\hline $162-7-6$ & 61 & Upper Eocene & $\begin{array}{l}\text { Medium brown rad ooze, ferruginous, } \\
\text { clayey, slightly mottled. }\end{array}$ & 10.9 & 10.7 & 0.43 & 0.42 & 1.27 & 603 & 19.6 & 2.69 & 2.9 & 0.18 & 612 & 35.5 & 35.8 & 71 & 7.6 \\
\hline $8-6$ & 70 & Middle Eocene & $\begin{array}{l}\text { Yellowish brown nanno-rad chalk } \\
\text { ooze, slight mottling. }\end{array}$ & 10.9 & 10.7 & 0.43 & 0.41 & 1.25 & 600 & 19.6 & 2.66 & 0.7 & 0.04 & 608 & 35.5 & 35.5 & 58 & 7.6 \\
\hline $17-3$ & 147 & Middle Eocene & Yellowish brown ferruginous clay. & 10.7 & 10.5 & 0.42 & 0.40 & 1.21 & 588 & 19.2 & 2.52 & 1.3 & 0.08 & 594 & 34.5 & 34.6 & - & 7.4 \\
\hline \multicolumn{19}{|c|}{ Holes 163 and $163 \mathrm{~A}\left(11^{\circ} 14.7^{\prime} \mathrm{N}, 150^{\circ} 17.5^{\prime} \mathrm{W}\right.$, water depth $5320 \mathrm{~m}, 200 \mathrm{~km}$ south of Clarion Fracture Zone) } \\
\hline $163-2-4$ & 5 & Upper Oligocene & $\begin{array}{l}\text { Medium brown zeolitic radiolarian } \\
\text { clay. }\end{array}$ & 10.7 & 10.5 & 0.44 & 0.39 & 1.23 & 591 & 19.2 & 2.65 & 1.9 & 0.11 & 600 & 34.7 & 35.2 & 70 & 7.3 \\
\hline $163 \mathrm{~A}-1-4$ & 144 & $?$ & $\begin{array}{l}\text { Dark yellowish brown zeolitic clay with } \\
\text { with very pale yellow mottles. }\end{array}$ & 10.7 & 10.4 & 0.44 & 0.40 & 1.26 & 587 & 19.3 & 2.51 & 2.6 & 0.16 & 598 & 34.8 & 34.9 & 49 & 7.4 \\
\hline $163-23-6$ & 241 & Upper Campanian & Varicolored nanno chalk. & 10.6 & 10.4 & 0.41 & 0.47 & 1.16 & 578 & 19.1 & 2.16 & 2.7 & 0.17 & 586 & 34.1 & 34.1 & 27 & 7.4 \\
\hline LEG 17 & & & & & & & & & & & & & & & & & & \\
\hline \multicolumn{19}{|c|}{ Hole $164\left(13^{\circ} 12.1^{\prime} \mathrm{N}, 161^{\circ} 31.0^{\prime} \mathrm{W}\right.$, water depth $5485 \mathrm{~m}$, Clarion-Molokai block) } \\
\hline Surface ocean & $\mathrm{n}$ water & & & 10.6 & 10.5 & 0.38 & 0.41 & 1.28 & 592 & 19.1 & 2.67 & 2.7 & 0.16 & 597 & 34.6 & 34.9 & - & - \\
\hline $164-1-6$ & 43 & Lower Miocene & $\begin{array}{l}\text { Very dark grayish brown zeolitic } \\
\text { clay; very soft, disturbed. }\end{array}$ & 10.7 & 10.6 & 0.48 & 0.39 & 1.22 & 591 & 19.1 & 2.60 & 2.9 & 0.18 & 597 & 34.7 & 35.2 & - & 7.3 \\
\hline $3-2$ & 52 & Lower Oligocene & $\begin{array}{l}\text { Dark reddish brown to dark brown } \\
\text { zeolitic clay; radiolarian rich. }\end{array}$ & 10.8 & 10.6 & 0.50 & 0.40 & 1.22 & 593 & 19.3 & 2.55 & 2.9 & 0.18 & 602 & 35.0 & 35.2 & - & 7.2 \\
\hline $7-2$ & 86 & $\begin{array}{c}\text { Upper Cretaceous } \\
?\end{array}$ & $\begin{array}{l}\text { Dark brown, dark yellowish brown, } \\
\text { and grayish orange zeolitic clay; sam- } \\
\text { ple probably contaminated by drilling } \\
\text { mud. }\end{array}$ & 9.8 & 9.5 & 0.42 & 0.48 & 1.04 & 532 & 17.6 & 2.28 & 4.1 & 0.25 & 548 & 31.9 & 32.4 & 48 & 7.4 \\
\hline $10-3$ & 115 & $\begin{array}{l}\text { Santonian- } \\
\text { Campanian (?) }\end{array}$ & $\begin{array}{l}\text { Dark yellowish brown, brownish } \\
\text { black, and grayish orange zeolitic } \\
\text { clay; stiff and plastic }\end{array}$ & 10.7 & 10.6 & 0.47 & 0.58 & 1.18 & 589 & 19.4 & 2.45 & 3.0 & 0.18 & 601 & 35.0 & 35.2 & 44 & 7.3 \\
\hline $19-4$ & 200 & $\begin{array}{l}\text { Upper Cretaceous } \\
\text { (?) }\end{array}$ & $\begin{array}{l}\text { Grayish red, yellowish brown, and } \\
\text { brown zeolitic clay; porcelaneous } \\
\text { chert and claystone fragments. }\end{array}$ & 10.6 & 10.4 & 0.40 & 0.66 & 1.14 & 587 & 19.2 & 2.52 & 3.3 & 0.20 & 598 & 34.7 & 35.2 & - & - \\
\hline \multicolumn{19}{|c|}{ Hole $165 \mathrm{~A}\left(08^{\circ} 10.7^{\prime} \mathrm{N}, 164^{\circ} 51.6^{\prime} \mathrm{W}\right.$, water depth $5053 \mathrm{~m}$, Line Island seamount chain) } \\
\hline $\begin{array}{r}165 \mathrm{~A}-6-5 \\
12-5\end{array}$ & $\begin{array}{l}134 \\
225\end{array}$ & $\begin{array}{l}\text { Early Oligocene } \\
\text { Middle Eocene }\end{array}$ & $\begin{array}{l}\text { White foram-nanno micrite and ooze. } \\
\text { White turbiditic nanno-rad ooze, and } \\
\text { light yellowish brown rad ooze; } \\
\text { distorted beds, alternating. }\end{array}$ & $\begin{array}{l}10.8 \\
10.8\end{array}$ & $\begin{array}{l}10.5 \\
10.6\end{array}$ & $\begin{array}{l}0.42 \\
0.39\end{array}$ & $\begin{array}{l}0.51 \\
0.53\end{array}$ & $\begin{array}{l}1.18 \\
1.19\end{array}$ & $\begin{array}{l}591 \\
596\end{array}$ & $\begin{array}{l}19.6 \\
19.6\end{array}$ & $\begin{array}{l}2.30 \\
2.33\end{array}$ & $\begin{array}{l}3.8 \\
3.1\end{array}$ & $\begin{array}{l}0.23 \\
0.19\end{array}$ & $\begin{array}{l}603 \\
604\end{array}$ & $\begin{array}{l}35.0 \\
35.0\end{array}$ & $\begin{array}{l}35.2 \\
35.2\end{array}$ & $\overline{52}$ & $\begin{array}{l}7.3 \\
7.4\end{array}$ \\
\hline
\end{tabular}




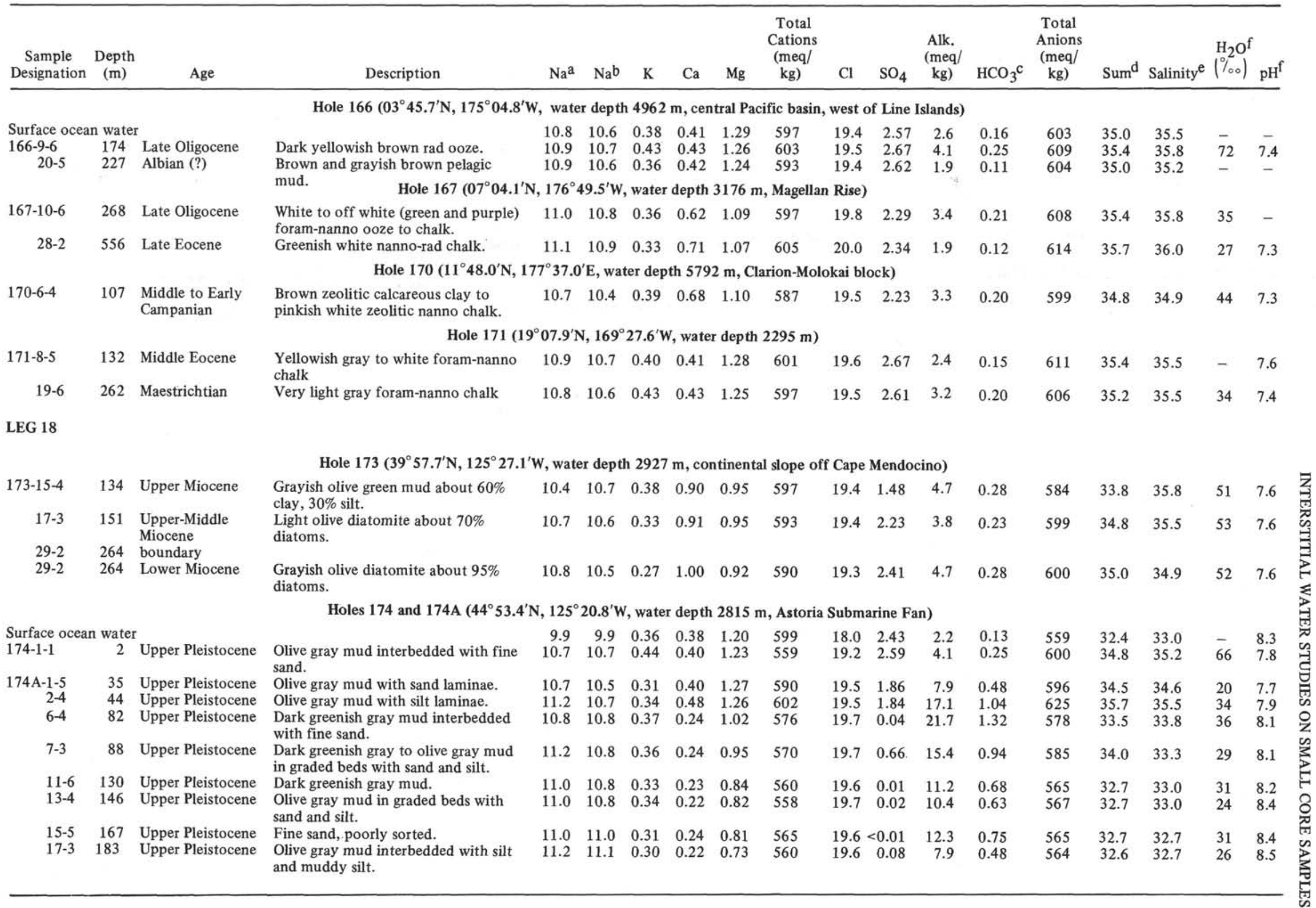




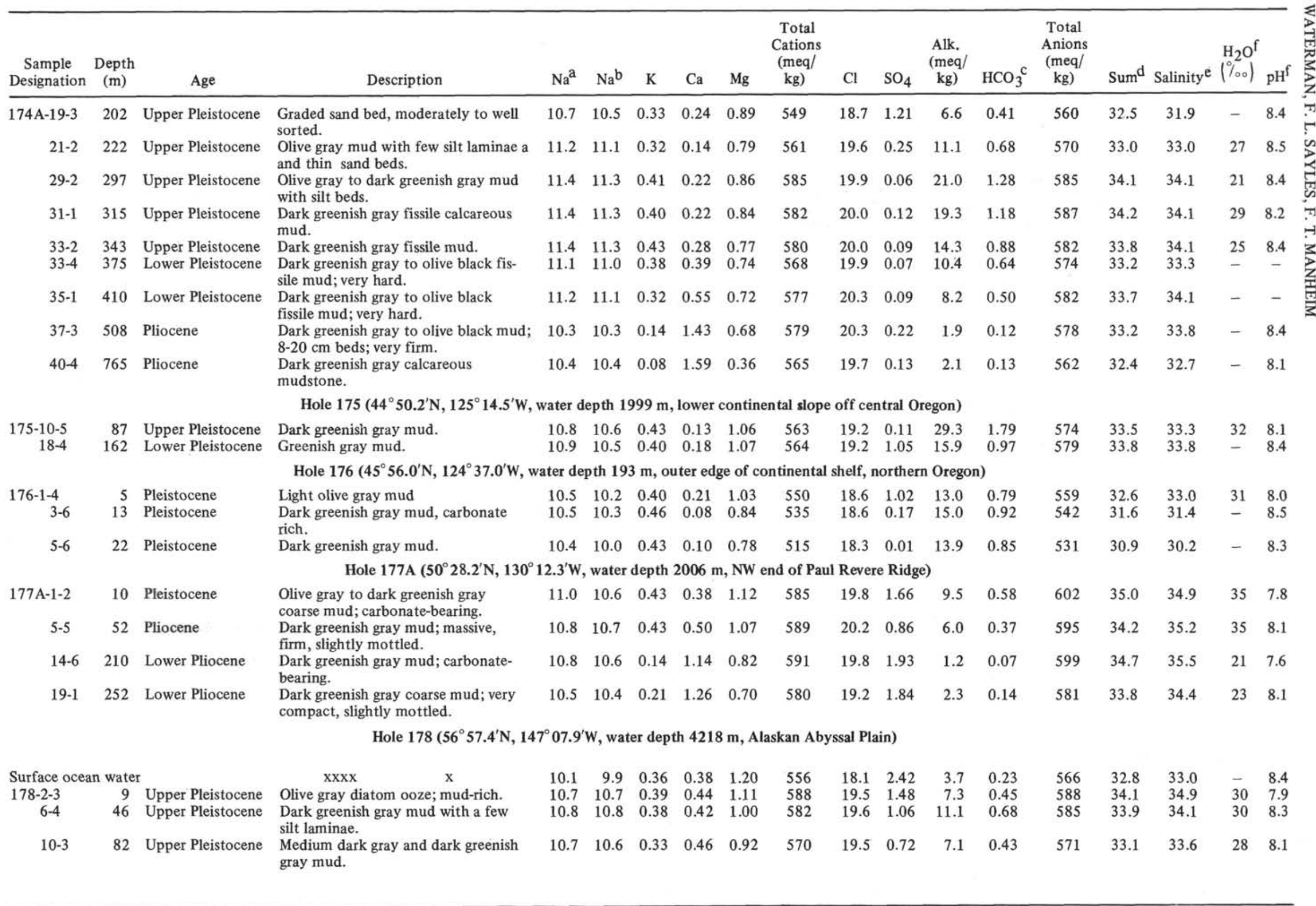




\begin{tabular}{|c|c|c|c|c|c|c|c|c|c|c|c|c|c|c|c|c|c|c|}
\hline $\begin{array}{c}\text { Sample I } \\
\text { Designation }\end{array}$ & $\begin{array}{l}\text { Depth } \\
\text { (m) }\end{array}$ & Age & Description & $\mathrm{Na}^{\mathrm{a}}$ & $\mathrm{Nab}$ & $\mathrm{K}$ & $\mathrm{Ca}$ & $\mathrm{Mg}$ & $\begin{array}{c}\text { Total } \\
\text { Cations } \\
\text { (meq/ } \\
\mathrm{kg})\end{array}$ & $\mathrm{Cl}$ & $\mathrm{SO}_{4}$ & $\begin{array}{l}\text { Alk. } \\
(\mathrm{meq} / \\
\mathrm{kg})\end{array}$ & $\mathrm{HCO}_{3}{ }^{\mathrm{c}}$ & $\begin{array}{c}\text { Total } \\
\text { Anions } \\
\text { (meq/ } \\
\text { kg) }\end{array}$ & Sumd & Salinitye & $\begin{array}{l}\mathrm{H}_{2} \mathrm{O}^{\mathrm{f}} \\
(\% \circ)\end{array}$ & $\mathrm{pH}^{\mathrm{f}}$ \\
\hline $178-15-2$ & 125 & Upper Pleistocene & $\begin{array}{l}\text { Dark greenish gray mud with trace to } \\
20 \% \text { diatoms. }\end{array}$ & 10.6 & 10.7 & 0.32 & 0.61 & 0.79 & 569 & 19.4 & 0.43 & 8.2 & 0.50 & 565 & 32.6 & 32.7 & 36 & 8.4 \\
\hline $19-1$ & 160 & Upper Pleistocene & Medium dark gray mud. & 10.6 & 10.5 & 0.28 & 0.67 & 0.72 & 557 & 19.3 & 0.40 & 5.4 & 0.33 & 559 & 32.3 & 32.4 & 23 & 8.4 \\
\hline $23-3$ & 198 & Pleistocene (?) & $\begin{array}{l}\text { Olive gray and dark greenish gray } \\
\text { mud; } 65 \% \text { clay, } 35 \% \text { silt. }\end{array}$ & 10.6 & 10.6 & 0.26 & 0.75 & 0.61 & 556 & 19.4 & 0.14 & 4.5 & 0.28 & 556 & 32.0 & 32.4 & 40 & 8.8 \\
\hline $27-1$ & 230 & Pliocene & $\begin{array}{l}\text { Olive gray mud with a few silt } \\
\text { laminae. }\end{array}$ & 10.6 & 10.5 & 0.21 & 0.70 & 0.66 & 553 & 19.2 & 0.47 & 3.1 & 0.19 & 556 & 32.0 & 31.9 & 23 & 8.1 \\
\hline $29-5$ & 255 & Pliocene & Olive gray mud with silt laminae. & 10.6 & 10.5 & 0.21 & 0.66 & 0.62 & 544 & 19.2 & 0.29 & 3.2 & 0.19 & 551 & 31.8 & 31.4 & 25 & 8.5 \\
\hline $31-2$ & 298 & Pliocene & $\begin{array}{l}\text { Dark greenish gray mud; } 20-30 \% \\
\text { diatoms. }\end{array}$ & 10.4 & 10.3 & 0.26 & 0.52 & 0.80 & 547 & 19.0 & 0.59 & 4.1 & 0.25 & 551 & 31.8 & 32.4 & 37 & 8.2 \\
\hline $33-3$ & 318 & Lower Pliocene & $\begin{array}{l}\text { Olive gray, olive black, and dark } \\
\text { greenish gray fine mud. }\end{array}$ & 10.6 & 10.5 & 0.28 & 0.62 & 0.73 & 554 & 19.2 & 0.27 & 11.3 & 0.69 & 560 & 32.4 & 32.7 & - & 8.6 \\
\hline $37-4$ & 358 & Middle Miocene & $\begin{array}{l}\text { Green gray muddy diatomite inter- } \\
\text { bedded with olive gray diatom mud. }\end{array}$ & 10.5 & 10.6 & 0.29 & 0.61 & 0.74 & 558 & 19.4 & 0.16 & 7.5 & 0.46 & 557 & 32.2 & 32.7 & 44 & 8.2 \\
\hline $47-1$ & 506 & Middle Miocene & Dark greenish gray mud; very hard. & 10.5 & 10.5 & 0.17 & 0.92 & 0.63 & 558 & 19.4 & 0.04 & 9.9 & 0.60 & 559 & 32.3 & 32.2 & 24 & 8.3 \\
\hline $50-1$ & 629 & Middle Miocene & $\begin{array}{l}\text { Olive gray and dark greenish gray } \\
\text { mud; } 65 \% \text { clay, } 35 \% \text { silt. }\end{array}$ & 10.7 & 10.6 & 0.18 & 1.09 & 0.46 & 559 & 19.7 & 0.04 & 2.5 & 0.15 & 560 & 32.3 & 32.2 & 30 & 9.0 \\
\hline $52-2$ & 690 & Middle Miocene & $\begin{array}{l}\text { Olive gray mud; hard; } 60 \% \text { clay, } \\
40 \% \text { silt. }\end{array}$ & 10.8 & 10.7 & 0.23 & 1.01 & 0.42 & 557 & 19.6 & 0.06 & 5.2 & 0.32 & 559 & 32.4 & 31.9 & 40 & 8.3 \\
\hline $53-2$ & 718 & Middle Miocene & $\begin{array}{l}\text { Olive gray and dark greenish } \\
\text { gray mud; hard. }\end{array}$ & 10.8 & 10.8 & 0.26 & 1.03 & 0.44 & 564 & 19.7 & 0.10 & 4.8 & 0.29 & 562 & 32.6 & 33.0 & 27 & 8.3 \\
\hline \multicolumn{19}{|c|}{ Hole $179\left(56^{\circ} 24.5^{\prime} \mathrm{N}, 145^{\circ} 59.3^{\prime} \mathrm{W}\right.$, water depth $3781 \mathrm{~m}$, Alaskan Abyssal Plain) } \\
\hline $179-5-2$ & 34 & Pleistocene & Greenish gray sandy mud; soft. & 10.9 & 10.7 & 0.41 & 0.48 & 1.23 & 601 & 19.4 & 2.68 & 4.4 & 0.27 & 609 & 35.4 & 36.0 & 37 & 7.7 \\
\hline $11-3$ & 92 & Pleistocene & Black gravel tuff. & 10.8 & 10.6 & 0.45 & 0.41 & 1.21 & 591 & 19.3 & 2.59 & 3.2 & 0.19 & 602 & 35.0 & 35.2 & 47 & 7.5 \\
\hline \multicolumn{19}{|c|}{ Hole $180\left(57^{\circ} 21.8^{\prime} \mathrm{N}, 147^{\circ} 51.4^{\prime} \mathrm{W}\right.$, water depth $4923 \mathrm{~m}$, Eastern Aleutian Trench) } \\
\hline Surface ocean & $\mathrm{n}$ water & & & 10.1 & 10.0 & 0.36 & 0.39 & 1.20 & 560 & 18.2 & 2.53 & 2.2 & 0.14 & 567 & 32.9 & 32.7 & - & 8.4 \\
\hline $180-1-3$ & 3 & Holocene & $\begin{array}{l}\text { Dark greenish gray mud with inter- } \\
\text { bedded graded coarse silts. }\end{array}$ & 10.8 & 10.7 & 0.38 & 0.42 & 1.29 & 603 & 19.4 & 2.20 & 13.8 & 0.84 & 608 & 35.3 & 35.5 & 27 & 7.9 \\
\hline $2-4$ & 14 & Holocene & $\begin{array}{l}\text { Gray mud with thin interbedding } \\
\text { of coarse and medium silts. }\end{array}$ & 10.9 & 10.9 & 0.30 & 0.42 & 1.36 & 612 & 19.8 & 1.71 & 22.9 & 1.40 & 616 & 35.9 & 36.3 & 30 & 7.7 \\
\hline $4-3$ & 32 & Holocene & $\begin{array}{l}\text { Fine gray mud interbedded with } \\
\text { coarse and medium silts. }\end{array}$ & 10.9 & 10.8 & 0.32 & 0.29 & 1.34 & 601 & 19.8 & 1.14 & 24.3 & 1.48 & 606 & 35.3 & 35.5 & 27 & 7.7 \\
\hline $8-5$ & 72 & Holocene & $\begin{array}{l}\text { Gray mud with a few thin beds of } \\
\text { graded medium silts. }\end{array}$ & 10.9 & 10.8 & 0.30 & 0.36 & 1.26 & 600 & 19.8 & 0.65 & 29.1 & 1.78 & 602 & 35.0 & 35.8 & 26 & 8.0 \\
\hline $11(C C)$ & 124 & Holocene & Gray mud and medium silt. & - & 10.7 & 0.49 & 0.14 & 1.09 & 575 & 19.8 & - & - & - & - & - & - & - & 8.2 \\
\hline $12-2$ & 146 & Holocene & $\begin{array}{l}\text { Gray mud with thin beds and laminae } \\
\text { of silt. }\end{array}$ & 10.7 & 10.7 & 0.29 & 0.24 & 1.21 & 584 & 19.6 & 0.04 & 27.9 & 1.70 & 583 & 33.8 & 34.4 & 24 & 8.0 \\
\hline $13(\mathrm{CC})$ & 180 & Pleistocene & Gray mud. & 10.8 & 10.8 & 0.24 & 0.25 & 1.18 & 583 & 19.7 & 0.08 & 30.9 & 1.88 & 587 & 34.1 & 35.5 & - & 8.0 \\
\hline $15-3$ & 245 & Pleistocene & $\begin{array}{l}\text { Gray mud with interbedding of } \\
\text { graded silts. }\end{array}$ & 11.3 & 11.1 & 0.32 & 0.13 & 1.19 & 595 & 20.0 & 0.29 & 34.9 & 2.13 & 604 & 35.4 & 34.1 & - & 8.2 \\
\hline $17-3$ & 266 & Pleistocene & $\begin{array}{l}\text { Dark greenish gray diatom-bearing } \\
\text { mud. }\end{array}$ & 11.1 & 10.8 & 0.32 & 0.22 & 1.19 & 585 & 19.5 & 0.10 & 31.2 & 1.91 & 582 & 34.3 & 34.6 & 22 & 8.2 \\
\hline $18-4$ & 276 & Pleistocene & $\begin{array}{l}\text { Gray and dark greenish gray mud with } \\
\text { interbedding of graded silts and very } \\
\text { fine sand. }\end{array}$ & 11.0 & 10.8 & 0.32 & 0.23 & 1.21 & 587 & $19.7 t$ & $<0.01)$ & 41.2 & 2.51 & 597 & 35.0 & 35.2 & 50 & 8.1 \\
\hline
\end{tabular}


TABLE 1 - Continued

\begin{tabular}{|c|c|c|c|c|c|c|c|c|c|c|c|c|c|c|c|c|c|c|}
\hline $\begin{array}{l}\text { Sample } \\
\text { Designation }\end{array}$ & $\begin{array}{l}\text { Depth } \\
(\mathrm{m})\end{array}$ & Age & Description & $\mathrm{Na}^{\mathrm{a}}$ & $\mathrm{Na}^{\mathrm{b}}$ & K & $\mathrm{Ca}$ & $\mathrm{Mg}$ & $\begin{array}{c}\text { Total } \\
\text { Cations } \\
\text { (meq/ } \\
\mathrm{kg})\end{array}$ & $\mathrm{Cl}$ & $\mathrm{SO}_{4}$ & $\begin{array}{l}\text { Alk. } \\
\text { (meq/ } \\
\mathrm{kg})\end{array}$ & $\mathrm{HCO}_{3} \mathrm{c}$ & $\begin{array}{c}\text { Total } \\
\text { Anions } \\
\text { (meq/ } \\
\mathrm{kg})\end{array}$ & Sum $^{\mathrm{d}}$ & Salinity e & $\begin{array}{l}\mathrm{H}_{2} \mathrm{Of} \\
(\% \circ)\end{array}$ & $\mathrm{pH}^{\mathrm{f}}$ \\
\hline $180-19-2$ & 348 & Pleistocene & $\begin{array}{l}\text { Gray mud with interbedding of graded } \\
\text { silts and very fine sand. }\end{array}$ & 10.7 & 10.8 & 0.40 & 0.16 & 1.14 & 579 & 19.6 & 0.10 & 22.0 & 1.34 & 578 & 33.4 & 34.1 & 21 & 8.2 \\
\hline $20-5$ & 420 & Pleistocene & $\begin{array}{l}\text { Gray mud with interbedding of graded } \\
\text { coarse and medium silts. }\end{array}$ & 10.6 & 10.6 & 0.20 & 0.42 & 1.02 & 570 & 19.7 & $<0.01$ & 15.6 & 0.95 & 573 & 32.9 & 34.1 & 21 & 8.2 \\
\hline $22-6$ & 440 & Pleistocene & Gray mud with interbedded silt. & 10.6 & 10.5 & 0.18 & 0.40 & 0.97 & 563 & 19.6 & 0.15 & 8.5 & 0.52 & 564 & 32.4 & 33.0 & 19 & 8.2 \\
\hline $24-4$ & 456 & Pleistocene & $\begin{array}{l}\text { Gray mud with interbedding of } \\
\text { medium and fine silts. }\end{array}$ & 10.4 & 10.3 & 0.20 & 0.45 & 0.97 & 556 & 19.4 & 0.31 & 8.1 & 0.49 & 562 & 32.2 & 33.0 & 22 & 8.1 \\
\hline \multicolumn{19}{|c|}{ Hole $181\left(57^{\circ} 26.3^{\prime} \mathrm{N}, 148^{\circ} 27.9^{\prime} \mathrm{W}\right.$, water depth $3086 \mathrm{~m}$, landward wall of Aleutian Trench) } \\
\hline $181-7-3$ & 60 & Pleistocene & Medium gray mud; firm, uniform. & 10.3 & 10.4 & 0.30 & 0.24 & 1.15 & 568 & 19.7 & 0.05 & 6.0 & 0.37 & 562 & 32.1 & 33.8 & - & 8.3 \\
\hline $13-5$ & 120 & Pleistocene & $\begin{array}{l}\text { Medium gray to olive gray diatom- } \\
\text { bearing mud; firm to compact; uniform, } \\
\text { fine grained. }\end{array}$ & 10.3 & 10.3 & 0.25 & 0.35 & 1.11 & 562 & 19.5 & 0.07 & 8.5 & 0.52 & 561 & 32.1 & 33.8 & 24 & 7.9 \\
\hline $17-6$ & 159 & Pleistocene & $\begin{array}{l}\text { Medium gray fine mud; diatom- } \\
\text { bearing; firm to stiff. }\end{array}$ & 10.7 & 10.5 & 0.23 & 0.52 & 0.82 & 556 & 19.7 & 0.06 & 6.3 & 0.39 & 563 & 32.4 & 33.0 & 17 & 8.1 \\
\hline $20-1$ & 177 & Pleistocene & $\begin{array}{l}\text { Grayish black and greenish black mud; } \\
\text { indurated. }\end{array}$ & 10.4 & 10.4 & 0.12 & 1.06 & 0.50 & 547 & 19.2 & 0.24 & 3.6 & 0.22 & 549 & 31.7 & 31.9 & - & 8.4 \\
\hline \multicolumn{19}{|c|}{ Hole $182\left(57^{\circ} 53.0^{\prime} \mathrm{N}, 148^{\circ} 43.0^{\prime} \mathrm{W}\right.$, water depth $1419 \mathrm{~m}$, upper continental slope E of Kodiak Island) } \\
\hline $182-1-6$ & 8 & Pleistocene & Medium gray mud. & 10.6 & 10.4 & 0.43 & 0.21 & 1.09 & 565 & 19.0 & 1.43 & 8.8 & 0.54 & 573 & 33.3 & 33.6 & 24 & 8.1 \\
\hline
\end{tabular}

${ }^{a}$ Sodium determined by difference between anions and cations excluding $\mathrm{Na}$.

bodium determined by atomic absorption analysis.

${ }^{\mathrm{C}} \mathrm{HCO}_{3}^{-}$is calculated from total alkalinity, assuming this is entirely due to bicarbonate ion.

${ }^{\mathrm{d}}$ The sum incorporates the sodium values determined by difference.

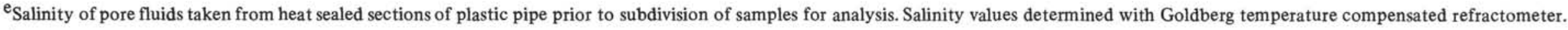

$\mathrm{f}_{\mathrm{pH}}$ and water content are taken from shipboard summaries. 
TABLE 2

Minor Constituents of Pore Fluids, Legs 16, 17, and 18. Concentrations in mg/kg (ppm).

\begin{tabular}{|c|c|c|c|c|c|c|c|}
\hline $\begin{array}{c}\text { Sample } \\
\text { Designation }\end{array}$ & $\begin{array}{l}\text { Depth } \\
\text { (m) }\end{array}$ & Age & Description & $\mathrm{Sr}$ & $\mathrm{Ba}$ & $\begin{array}{l}\mathrm{Si} \\
(\mathrm{col} .)^{\mathrm{a}}\end{array}$ & $\underset{(\text { spec.) }}{\mathrm{Si}}$ \\
\hline
\end{tabular}

Hole 155

\begin{tabular}{|c|c|c|c|c|c|c|c|}
\hline \multirow{2}{*}{\multicolumn{4}{|c|}{ Surface ocean water }} & & & & \\
\hline & & & & 7.6 & $<0.1$ & $<0.1$ & - \\
\hline $155-1-6$ & 442 & Upper Miocene & Olive and light olive gray marl, mottled. & 50 & 16 & 2.8 & - \\
\hline $2-6$ & 451 & Upper Miocene & Medium greenish gray mudstone. & 57 & 16 & 3.4 & - \\
\hline 3-6 & 460 & Upper Miocene & Varicolored olive gray marly clay. & 62 & 19 & 3.7 & - \\
\hline 4-6 & 469 & Upper Miocene & Olive gray claystone, massive, waxy. & 63 & 21 & 7.5 & - \\
\hline $5-6$ & 478 & Upper Miocene & Olive gray claystone. & 72 & 19 & 3.6 & - \\
\hline $6-4$ & 484 & Middle Miocene & $\begin{array}{l}\text { Greenish gray and dusky yellow green marl } \\
\text { with olive gray pyritic mottles. }\end{array}$ & 76 & 1.1 & 3.3 & - \\
\hline $7-2$ & 490 & Middle Miocene & $\begin{array}{l}\text { Light olive gray dolomitic chalk, massive, } \\
\text { well indurated. }\end{array}$ & 72 & 1.7 & 4.2 & - \\
\hline $8(\mathrm{CC})$ & 506 & Middle Miocene & Yellowish to light olive gray chalk-marl. & 71 & 0.34 & 5.1 & - \\
\hline $9(\mathrm{CC})$ & 515 & Middle Miocene & Light gray chalk ooze. & 70 & 0.43 & 6.4 & - \\
\hline & & & Hole 157 & & & & \\
\hline $157-16-6$ & 144 & Upper Pliocene & $\begin{array}{l}\text { Pale olive nanno chalk ooze, mottled, } \\
\mathrm{H}_{2} \mathrm{~S} \text { odor. }\end{array}$ & 13.6 & $<0.1$ & 36 & 34 \\
\hline $36-3$ & 327 & Upper Miocene & $\begin{array}{l}\text { Light greenish gray to yellowish gray nanno } \\
\text { chalk, mottles. }\end{array}$ & 33 & $<0.1$ & 49 & 47 \\
\hline $39-1$ & 346 & Upper Miocene & $\begin{array}{l}\text { Yellowish gray to pale olive nanno chalk, } \\
\text { mottled and burrowed. }\end{array}$ & 46 & $<0.1$ & 35 & 37 \\
\hline & & & Hole 158 & & & & \\
\hline $158-2-5$ & 15 & Pleistocene & $\begin{array}{l}\text { Grayish to dusky yellow green foram-nanno } \\
\text { chalk ooze. }\end{array}$ & 13 & $<0.1$ & 18 & 18 \\
\hline $13-5$ & 114 & Upper Miocene & $\begin{array}{l}\text { Medium greenish gray nanno chalk ooze, } \\
\text { forams and rads abundant, light olive gray } \\
\text { mottling. }\end{array}$ & 35 & $<0.1$ & 31 & 32 \\
\hline $33-2$ & 293 & Middle Miocene & $\begin{array}{l}\text { Grayish to dusky yellow green nanno chalk } \\
\text { with forams, nannos, rads, and silicoflagellates. }\end{array}$ & 36 & $<0.1$ & 36 & 35 \\
\hline & & & Hole 159 & & & & \\
\hline $159-2-6$ & 16 & Upper Miocene & Dark to dusky yellowish brown clay. & 8.0 & $<0.1$ & 17 & 24 \\
\hline $12-5$ & 105 & Lower Miocene & Brown nanno marl ooze with mottling. & 9.6 & $<0.1$ & 11 & 9 \\
\hline & & & Hole 160 & & & & \\
\hline $160-2-4$ & 14 & $?$ & Medium brown and grayish orange zeolitic clay. & 8.0 & $<0.1$ & 14 & 14 \\
\hline 6-5 & 51 & Upper Oligocene & Pale yellowish orange nanno chalk ooze. & 8.6 & $<0.1$ & 18 & 16 \\
\hline & & & Holes 161 and $161 \mathrm{~A}$ & & & & \\
\hline $161-9-4$ & 76 & Upper Oligocene & $\begin{array}{l}\text { White nanno chalk ooze, very thin beds of } \\
\text { yellowish gray nanno chalk ooze. }\end{array}$ & 9.2 & $<0.1$ & 21 & 18 \\
\hline $161 \mathrm{~A}-11-4$ & 214 & Upper Eocene & $\begin{array}{l}\text { Dark yellowish brown clay and ferruginous } \\
\text { aggregates, intense burrowing and mottling. }\end{array}$ & 9.4 & $<0.1$ & 30 & 30 \\
\hline & & & Hole 162 & & & & \\
\hline Surface oce & ater & & & 7.8 & $<0.1$ & $<0.1$ & $<7$ \\
\hline $162-7-6$ & 61 & Upper Eocene & $\begin{array}{l}\text { Medium brown rad ooze, ferruginous, clayey, } \\
\text { slightly mottled. }\end{array}$ & 8.9 & $<0.1$ & 23 & 22 \\
\hline $8-6$ & 70 & Middle Eocene & $\begin{array}{l}\text { Yellowish brown nanno-rad chalk ooze, slight } \\
\text { mottling. }\end{array}$ & 8.9 & 0.10 & 22 & 19 \\
\hline $17-3$ & 147 & Middle Eocene & Yellowish brown ferruginous clay. & 7.5 & 0.11 & 10 & - \\
\hline & & & Holes 163 and $163 \mathrm{~A}$ & & & & \\
\hline $163-2-4$ & 5 & Upper Oligocene & Medium brown zeolitic radiolarian clay. & 8.0 & $<0.1$ & 18 & - \\
\hline $163 \mathrm{~A}-1-4$ & 144 & $?$ & $\begin{array}{l}\text { Dark yellowish brown zeolitic clay with very pa } \\
\text { pale yellow mottles. }\end{array}$ & 8.0 & $<0.1$ & 23 & 21 \\
\hline $163-23-6$ & 241 & Upper Campanian & Varicolored nanno chalk. & 9.6 & $<0.1$ & 24 & 22 \\
\hline
\end{tabular}


TABLE 2 - Continued

\begin{tabular}{|c|c|c|c|c|c|c|c|}
\hline $\begin{array}{c}\text { Sample } \\
\text { Designation }\end{array}$ & $\begin{array}{c}\text { Depth } \\
\text { (m) }\end{array}$ & Age & Description & $\mathrm{Sr}$ & $\mathrm{Ba}$ & $\begin{array}{l}\mathrm{Si} \\
(\mathrm{col} .)^{\mathrm{a}}\end{array}$ & $\underset{(\text { spec. })^{\mathrm{b}}}{\mathrm{Si}}$ \\
\hline
\end{tabular}

Leg 17

Hole 164

Surface ocean water

\begin{tabular}{|c|c|c|}
\hline $164-1-6$ & 43 & $\begin{array}{l}\text { Lower Miocene } \\
\text { Low }\end{array}$ \\
\hline $3-2$ & 52 & Lower Oligocene \\
\hline $7-2$ & 86 & Upper Cretaceous \\
\hline $10-3$ & 115 & $\begin{array}{l}\text { Santonian- } \\
\text { Campanian (?) }\end{array}$ \\
\hline $19-4$ & 200 & $\begin{array}{l}\text { Upper Cretaceous } \\
\text { (?) }\end{array}$ \\
\hline
\end{tabular}

$165 \mathrm{~A}-6-5$

$12-5$
134

225
Early Oligocene Middle Eocene

\begin{tabular}{|c|c|c|}
\hline \multicolumn{3}{|c|}{ Surface ocean water } \\
\hline $166-9-6$ & 174 & Late Oligocene \\
\hline $20-5$ & 227 & Albian (?) \\
\hline $167-10-6$ & 268 & Late Oligocene \\
\hline $28-2$ & 556 & Late Eocene \\
\hline $170-6-4$ & 107 & $\begin{array}{l}\text { Middle to Early } \\
\text { Campanian }\end{array}$ \\
\hline $171-8-5$ & 132 & Middle Eocene \\
\hline $19-6$ & 262 & Maestrichtian \\
\hline
\end{tabular}

Leg 18

$\begin{array}{rrl}173-15-4 & 134 & \text { Upper Miocene } \\ 17-3 & 151 & \begin{array}{l}\text { Upper-Middle } \\ \text { Miocene boundary }\end{array} \\ 29-2 & 264 & \begin{array}{l}\text { Lower Miocene } \\ \text { Low }\end{array}\end{array}$

Very dark grayish brown zeolitic clay; very soft, disturbed.

Dark reddish brown to dark brown zeolitic clay; radiolarian-rich.

Dark brown, dark yellowish brown, and grayish orange zeolitic clay; sample probably contaminated by drilling mud.

Dark yellowish brown, brownish black, and grayish orange zeolitic clay; stiff and plastic. Grayish red, yellowish brown, and brown zeolitic clay; porcelaneous chert and claystone fragments.

\section{Hole 165A}

White foram-nanno micrite and ooze. White turbiditic nanno-rad ooze, and light yellowish brown rad ooze; distorted beds, alternating.

$\begin{array}{llll}8.6 & <0.05 & <0.1 & <7 \\ 8.3 & <0.05 & 15 & 15 \\ 8.2 & <0.05 & 22 & 21 \\ 8.8 & <0.05 & 21 & 20 \\ 9.3<0.1 & 22 & 20 \\ 9.7 & <0.1 & 31 & 22\end{array}$

\section{Hole 166}

Dark yellowing brown rad ooze

Brown and grayish brown pelagic mud.

Hole 167

White to off white (green and purple) foramnanno ooze to chalk.

Greenish white nanno-rad chalk.

Hole 170

Brown zeolitic calcareous clay to pinkish white zeolitic nanno chalk.

$\begin{array}{lll}11.9 & 0.10 & 31 \\ 13.0 & 0.13 & 33\end{array}$

\section{Hole 171}

Yellowish gray to white foram-nanno chalk. Very light gray foram-nanno chalk.

$\begin{array}{rrrr}8.7 & <0.1 & 5.0 & <7 \\ 8.3 & <0.1 & 24 & 21 \\ 8.3 & <0.1 & 18 & 23 \\ & & & \\ 63 & <0.21 & 27 & 22 \\ 50 & <0.1 & 33 & 30 \\ & & & \\ 11.8 & - & 25 & 23 \\ & & & \\ & & & 16 \\ 8.6 & <0.1 & 17 & 19 \\ 8.2 & 0.1 & 18 & \end{array}$

\section{Hole 173}

Grayish olive green mud about $60 \%$ clay, $30 \%$ silt.

Light olive diatomite about $70 \%$ diatoms.

Grayish olive diatomite about $95 \%$ dia toms.

$\begin{array}{rrrr}10.8 & 0.1 & 29 & - \\ 10.7 & 0.1 & 29 & 30 \\ 10.9 & <0.1 & 36 & 38\end{array}$

Holes 174 and 174A

Surface ocean water

174-1-1

$174 \mathrm{~A}-1-5$

$2-4$

$6-4$

$7-3$

11-6

$13-4$

15-5

17-3

19-3

21-2
2

35

44

82

88

130

146

167

183

202

222
Upper Pleistocene Upper Pleistocene Upper Pleistocene Upper Pleistocene

Upper Pleistocene

Upper Pleistocene

Upper Pleistocene

Upper Pleistocene

Upper Pleistocene

Upper Pleistocene

Upper Pleistocene
Olive gray mud interbedded with fine sand.

Olive gray mud with sand laminae.

Olive gray mud with silt laminae.

Dark greenish gray mud interbedded with fine sand.

Dark greenish gray to olive gray mud in graded beds with sand and silt.

Dark greenish gray mud.

Olive gray mud in

Fine sand, poorly sorted.

Olive gray mud interbedded with silt and muddy silt.

Graded sand bed, moderately to well sorted.

Olive gray mud with few silt laminae and thin sand beds.

$\begin{array}{llll}7.7 & <0.1 & <0.1 & <7 \\ 10 & 0.03 & 16 & 13 \\ 11.9 & 0.06 & 12 & 13 \\ 11.9 & 0.2 & 13 & 19 \\ 13 & 3 & 12 & 14 \\ 11 & 1.3 & 8.6 & 13 \\ 12 & 9.1 & 14 & - \\ 11 & 2.0 & 7.1 & 8 \\ 12 & 3.5 & 8.5 & - \\ 12 & 2.2 & 8.1 & 8 \\ 10.1 & 1.6 & 6.6 & 8 \\ 10.3 & 3.0 & 8.5 & 9\end{array}$


TABLE 2 - Continued

\begin{tabular}{|c|c|c|c|c|c|c|c|}
\hline $\begin{array}{l}\text { Sample } \\
\text { Designation }\end{array}$ & $\begin{array}{l}\text { Depth } \\
(\mathrm{m})\end{array}$ & Age & Description & $\mathrm{Sr}$ & $\mathrm{Ba}$ & $\begin{array}{c}\mathrm{Si} \\
(\text { col. })^{\mathrm{a}}\end{array}$ & $\underset{\text { (spec.) }^{\mathrm{b}}}{\mathrm{Si}}$ \\
\hline $29-2$ & 297 & Upper Pleistocene & $\begin{array}{l}\text { Olive gray to dark greenish gray mud with } \\
\text { silt beds. }\end{array}$ & 11.5 & 18 & 11 & 17 \\
\hline $31-1$ & 315 & Upper Pleistocene & Dark greenish gray fissile calcareous mud. & 12 & 22 & 16 & 17 \\
\hline $33-2$ & 343 & Upper Pleistocene & Dark greenish gray fissile mud. & 12 & 16 & 12 & 14 \\
\hline $34-4$ & 375 & Lower Pleistocene & $\begin{array}{l}\text { Dark greenish gray to olive black fissile mud; } \\
\text { very hard. }\end{array}$ & 12.5 & 13 & 14 & 12 \\
\hline $35-1$ & 410 & Lower Pleistocene & $\begin{array}{l}\text { Dark greenish gray to olive black fissile mud; } \\
\text { very hard. }\end{array}$ & 10.5 & 11 & 14 & - \\
\hline $37-3$ & 508 & Pliocene & $\begin{array}{l}\text { Dark greenish gray to olive black mud; } 8-20 \mathrm{~cm} \\
\text { beds; very firm. }\end{array}$ & 7.8 & 1.6 & 5.6 & $<7$ \\
\hline $40-4$ & \multicolumn{7}{|c|}{ Hole 175} \\
\hline \multirow[t]{2}{*}{$18-4$} & $\begin{array}{r}87 \\
162\end{array}$ & $\begin{array}{l}\text { Upper Pleistocene } \\
\text { Lower Pleistocene }\end{array}$ & $\begin{array}{l}\text { Dark greenish gray mud. } \\
\text { Greenish gray mud. }\end{array}$ & $\begin{array}{l}9.9 \\
8.7\end{array}$ & ${ }^{17} 0.33$ & $\begin{array}{l}20 \\
16\end{array}$ & $\begin{array}{l}20 \\
26\end{array}$ \\
\hline & \multicolumn{7}{|c|}{ Hole 176} \\
\hline $\begin{array}{r}176-1-4 \\
3-6 \\
5-6\end{array}$ & $\begin{array}{r}5 \\
13 \\
22\end{array}$ & $\begin{array}{l}\text { Pleistocene } \\
\text { Pleistocene } \\
\text { Pleistocene }\end{array}$ & $\begin{array}{l}\text { Light olive gray mud. } \\
\text { Dark greenish gray mud, carbonate-rich. } \\
\text { Dark greenish gray mud. }\end{array}$ & $\begin{array}{l}7.1 \\
7.8 \\
9.1\end{array}$ & $\begin{array}{l}0.16 \\
0.64 \\
2.6\end{array}$ & $\begin{array}{l}16 \\
14 \\
19\end{array}$ & $\begin{array}{l}22 \\
18 \\
21\end{array}$ \\
\hline $5-6$ & \multicolumn{7}{|c|}{ Hole $177 \mathrm{~A}$} \\
\hline $177 \mathrm{~A}-1-2$ & 10 & Pleistocene & $\begin{array}{l}\text { Olive gray to dark greenish gray coarse mud; } \\
\text { carbonate-bearing. }\end{array}$ & 8.6 & $<0.1$ & 20 & 22 \\
\hline $5-5$ & 52 & Pliocene & $\begin{array}{l}\text { Dark greenish gray mud; massive, firm, slightly } \\
\text { mottled. }\end{array}$ & 9.1 & 0.15 & 22 & 22 \\
\hline $14-6$ & 210 & Lower Pliocene & Dark greenish gray mud; carbonate-bearing. & 11.8 & 0.27 & 15 & 17 \\
\hline \multirow[t]{2}{*}{$19-1$} & 252 & Lower Pliocene & $\begin{array}{l}\text { Dark greenish gray coarse mud; very compact, } \\
\text { slightly mottled. }\end{array}$ & 16.0 & 0.54 & 4.5 & $<7$ \\
\hline & \multicolumn{7}{|c|}{ Hole 178} \\
\hline \multicolumn{4}{|c|}{ Surface ocean water } & - & - & $<0.2$ & - \\
\hline $178-2-3$ & 9 & Upper Pleistocene & Olive gray diatom ooze; mud-rich. & 10.0 & 0.1 & 23 & 17 \\
\hline 6-4 & 46 & Upper Pleistocene & Dark greenish gray mud with a few silt laminae. & 10.8 & $<0.1$ & 20 & 22 \\
\hline $10-3$ & 82 & Upper Pleistocene & Medium dark gray and dark greenish gray mud. & 8.9 & 0.13 & 23 & 23 \\
\hline $15-2$ & 125 & Upper Pleistocene & $\begin{array}{l}\text { Dark greenish gray mud with trace to } 20 \% \\
\text { diatoms. }\end{array}$ & 10.4 & 0.2 & 24 & - \\
\hline $19-1$ & 160 & Upper Pleistocene & Medium dark gray mud. & 11.8 & 0.40 & 21 & 20 \\
\hline $23-3$ & 198 & Pleistocene (?) & $\begin{array}{l}\text { Olive gray and dark greenish gray mud; } 65 \% \\
\text { clay, } 35 \% \text { silt. }\end{array}$ & 13 & 1.0 & 13 & 12 \\
\hline $27-1$ & 230 & Pliocene & Olive gray mud with a few silt laminae. & 14 & 3.4 & 11 & 10 \\
\hline $29-5$ & 255 & Pliocene & Olive gray mud with silt laminae. & 14 & 11 & 6.4 & 8 \\
\hline $31-2$ & 298 & Pliocene & Dark greenish gray mud; $20-30 \%$ diatoms. & 13 & 7.9 & 19 & 22 \\
\hline $33-3$ & 318 & Lower Pliocene & $\begin{array}{l}\text { Olive gray, olive black, and dark greenish } \\
\text { gray fine mud. }\end{array}$ & 14 & 21 & 8.9 & 9 \\
\hline $37-4$ & 358 & Middle Miocene & $\begin{array}{l}\text { Green gray muddy diatomite interbedded with } \\
\text { olive gray diatom mud. }\end{array}$ & 13.6 & 27 & 17 & 24 \\
\hline $47-1$ & 506 & Middle Miocene & Dark greenish gray mud; very hard. & 18 & 23 & 6.4 & 8 \\
\hline $50-1$ & 629 & Middle Miocene & $\begin{array}{l}\text { Olive gray and dark greenish gray mud; } \\
65 \% \text { clay, } 35 \% \text { silt. }\end{array}$ & 14.8 & 23 & 8.2 & 10 \\
\hline $52-2$ & 690 & Middle Miocene & Olive gray mud; hard; $60 \%$ clay, $40 \%$ silt. & 16 & 59 & 29 & 35 \\
\hline \multirow[t]{2}{*}{$53-2$} & 718 & Middle Miocene & Olive gray and dark greenish gray mud; hard. & 20 & 18 & 21 & - \\
\hline & \multicolumn{7}{|c|}{ Hole 179} \\
\hline $179-5-2$ & 34 & Pleistocene & Greenish gray sandy mud; soft. & 10 & $(0.2)$ & 19 & 20 \\
\hline \multirow[t]{2}{*}{$11-3$} & 92 & Pleistocene & Black gravel tuff. & 9.2 & $(0.2)$ & 13 & 13 \\
\hline & \multicolumn{7}{|c|}{ Hole 180} \\
\hline \multicolumn{4}{|c|}{ Surface ocean water } & 7.8 & $<0.1$ & $<0.1$ & $<7$ \\
\hline $180-1-3$ & 3 & Holocene & $\begin{array}{l}\text { Dark greenish gray mud with interbedded } \\
\text { graded coarse silts. }\end{array}$ & 21 & $<0.1$ & 21 & 22 \\
\hline $2-4$ & 14 & Holocene & $\begin{array}{l}\text { Gray mud with thin interbedding of coarse } \\
\text { and medium silts. }\end{array}$ & 10.9 & 0.2 & 18 & 15 \\
\hline $4-3$ & 32 & Holocene & $\begin{array}{l}\text { Fine gray mud interbedded with coarse and } \\
\text { medium silts. }\end{array}$ & 9.1 & 0.1 & 21 & 23 \\
\hline $8-5$ & 72 & Holocene & $\begin{array}{l}\text { Gray mud with a few thin beds of graded } \\
\text { medium silts. }\end{array}$ & 9.0 & 0.3 & 17 & 21 \\
\hline $11(\mathrm{CC})$ & 124 & Holocene & Gray mud and medium silt. & - & - & - & - \\
\hline
\end{tabular}


TABLE 2 -Continued

\begin{tabular}{|c|c|c|c|c|c|c|c|}
\hline $\begin{array}{l}\text { Sample } \\
\text { Designation }\end{array}$ & $\begin{array}{l}\text { Depth } \\
(\mathrm{m})\end{array}$ & Age & Description & $\mathrm{Sr}$ & $\mathrm{Ba}$ & $\begin{array}{l}\mathrm{Si} \\
(\mathrm{col} .)^{\mathrm{a}}\end{array}$ & $\underset{(\text { spec. })^{\mathrm{b}}}{\mathrm{Si}}$ \\
\hline $12-2$ & 146 & Holocene & Gray mud with thin beds and laminae of silt. & 10.6 & 2.9 & 20 & 19 \\
\hline $13(\mathrm{CC})$ & 180 & Pleistocene & Gray mud. & 12 & 4.7 & 18 & 16 \\
\hline $15-3$ & 245 & Pleistocene & Gray mud with interbedding of graded silts. & 11 & 7 & - & 17 \\
\hline $17-3$ & 266 & Pleistocene & Dark greenish gray diatom-bearing mud. & 10 & 5.5 & 14 & - \\
\hline $18-4$ & 276 & Pleistocene & $\begin{array}{l}\text { Gray and dark greenish gray mud with } \\
\text { interbedding of graded silts and very fine sand. }\end{array}$ & 12 & 10.7 & 16 & 16 \\
\hline $19-2$ & 348 & Pleistocene & $\begin{array}{l}\text { Gray mud with interbedding of graded silts } \\
\text { and very fine sand. }\end{array}$ & 11 & 7.6 & 8.8 & 12 \\
\hline $20-5$ & 420 & Pleistocene & $\begin{array}{l}\text { Gray mud with interbedding of graded } \\
\text { coarse and medium silts. }\end{array}$ & 13 & 6.5 & 21 & 23 \\
\hline $22-6$ & 440 & Pleistocene & Gray mud with interbedded silt. & 13 & 4.2 & 13 & 17 \\
\hline \multirow[t]{2}{*}{$24-4$} & 456 & Pleistocene & $\begin{array}{l}\text { Gray mud with interbedding of medium and } \\
\text { fine silts. }\end{array}$ & 14 & 11.5 & 19 & 20 \\
\hline & & & Hole 181 & & & & \\
\hline $181-7-3$ & 60 & Pleistocene & Medium gray mud; firm, uniform. & 6.4 & 2.4 & 16 & 17 \\
\hline $13-5$ & 120 & Pleistocene & $\begin{array}{l}\text { Medium gray to olive gray diatom-bearing } \\
\text { mud; firm to compact; uniform, fine grained. }\end{array}$ & 12 & 7.9 & 25 & 27 \\
\hline $17-6$ & 159 & Pleistocene & $\begin{array}{l}\text { Medium gray fine mud; diatom-bearing; } \\
\text { firm to stiff. }\end{array}$ & 16 & 13 & 15 & - \\
\hline \multirow[t]{2}{*}{$20-1$} & 177 & Pleistocene & $\begin{array}{l}\text { Grayish black and greenish black mud; } \\
\text { indurated. }\end{array}$ & 22 & 23 & 3.7 & $<7$ \\
\hline & & & Hole 182 & & & & \\
\hline $182-1-6$ & 8 & Pleistocene & Medium gray mud. & 7.9 & 0.16 & 17 & 22 \\
\hline
\end{tabular}

$\mathrm{a}(\mathrm{col})=$. Colorimetric determination .

$\mathrm{b}($ spec $)=$ Emission spectrographic determination .

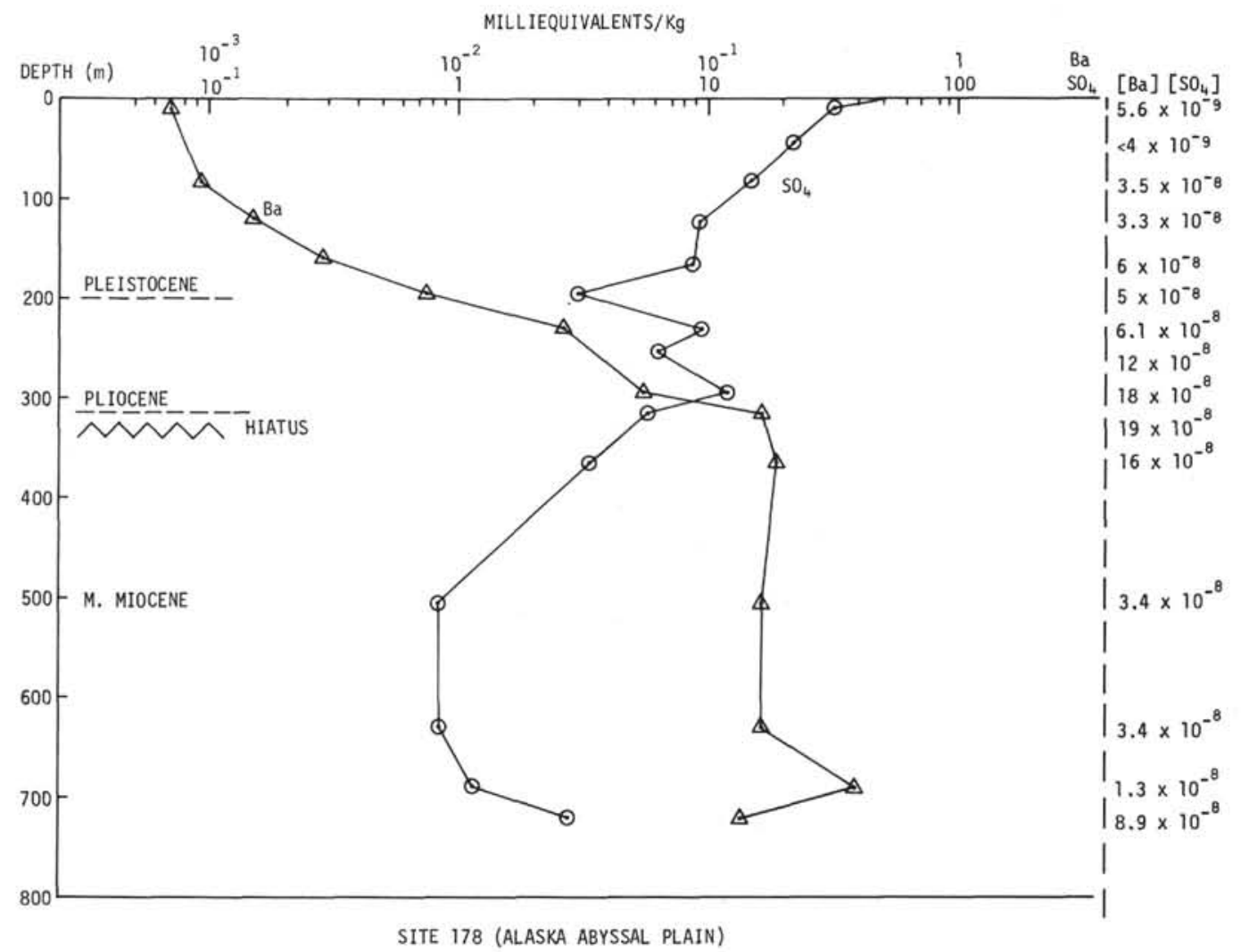

Figure 1. Distribution of interstitial $\mathrm{SO}_{4}=$ and $\mathrm{Ba}^{++}$with depth in Site 178. Note that molecular product, on right side of the diagram, utilizes moles $/ \mathrm{kg}$, whereas the profiles are given in meq/ $\mathrm{kg}$. For the purpose of establishing molar products, molarity (moles/liter) are usually employed, but the difference in units is not significant with respect to the large variation observed here. 